CASE REPORT

\title{
Multiple Nevus Achromicus Lesions: A Rare Entity
}

\author{
Roshni Kakitha ${ }^{1}$, Indradevi Radhakrishnan ${ }^{2}$
}

\begin{abstract}
Nevus achromicus is an uncommon birthmark characterized by a well-defined hypopigmented patch resembling a splash of paint. It is usually noted at birth or in early childhood. They do not progress and are mostly seen on the trunk. We report a 20-year-old young man with multiple nevus achromicus scattered over his trunk and limbs. Nevus achromicus is usually solitary, but sometimes it could be multiple wherein the distribution is segmental. Hence, this is a rare case of generalized multiple nevus achromicus and so worth reporting.
\end{abstract}

Keywords: Depigmentosus, Generalized multiple nevus achromicus, Hypopigmented macule.

SBV Journal of Basic, Clinical and Applied Health Science (2020): 10.5005/jp-journals-10082-02236

\section{INTRODUCTION}

Nevus depigmentosus or achromicus is a congenital pigmentary disorder that can occur in all sexes and races. ${ }^{1}$ It presents as a single large irregular area of hypo- or depigmentation in childhood and is static. It is strictly unilateral and usually limited to a single dermatome. ${ }^{1}$ Sometimes, the lesions may be small and multiple, but these are still unilateral and segmental. ${ }^{2}$

Nevus depigmentosus is caused by functionally defective melanocytes and abnormal melanosomes. ${ }^{2}$ Localized solitary lesions need to be differentiated from conditions like nevus anemicus, ash leaf macule, and vitiligo. Generalized lesions should be differentiated from hypomelanosis of Ito. ${ }^{2}$ Treatment is usually not required although cosmetic camouflage, phototherapy, and grafting can be done.'

\section{Case Description}

We report the case of a 20-year-old young man born to nonconsanguineously married couple. He came with multiple white patches on the skin, most of which were present since birth. Some of the patches had developed during his childhood. The patient was asymptomatic and had no history of developmental delay/ anomalies. There was no history of similar lesions over the oral or genital mucosa and no history of any other skin lesions,

On examination, multiple well-defined hypopigmented macules and patches distributed over the back, trunk, and upper and lower limbs were seen (Figs 1 to 3).

Based on the clinical findings, a differential diagnosis of ash leaf macules, multiple nevus anemicus, or achromicus was considered.

Diascopy test ruled out nevus anemicus. Absence of angiofibromas, shagreen patch, or history of epilepsy in the patient or family members ruled out tuberous sclerosis.

Hypomelanosis of Ito was ruled out as it is a unilaterally occurring condition.

A Wood's lamp examination showed no accentuation of the lesions, ruling out vitiligo.

Hansen's disease/leprosy was ruled out as most of the lesions were asymptomatic (no loss of sensations, sweating, or appendages) and present since childhood.

Dermoscopy showed normal skin markings, presence of welldefined margins, normal looking hair, and yellow and white dots in
${ }^{1}$ Titoria's Clinics, Noida, Uttar Pradesh, India

${ }^{2}$ Department of Dermatology, Venereology and Leprosy, Mahatma Gandhi Medical College and Research Institute, Puducherry, India

Corresponding Author: Roshni Kakitha, Titoria's Clinics, Noida, Uttar Pradesh, India, Phone: +91 7708541823, e-mail:k.roshni55@gmail.com How to cite this article: Kakitha R, Radhakrishnan I. Multiple Nevus Achromicus Lesions: A Rare Entity. J Basic Clin Appl Health Sci 2020;3(1): 38-39.

Source of support: Nil

Conflict of interest: None

polarized light. No vessels were seen and loss of pigment network was also observed (Fig. 4). ${ }^{3}$

Histopathology of the involved skin showed a normal number of melanocytes and was not suggestive of anything specific.

Based on the abovementioned exclusions, the patient was diagnosed with multiple nevus achromicus.

\section{Discussion}

Nevus depigmentosus or achromicus or achromic nevus is an uncommon disorder of pigmentation where an infant

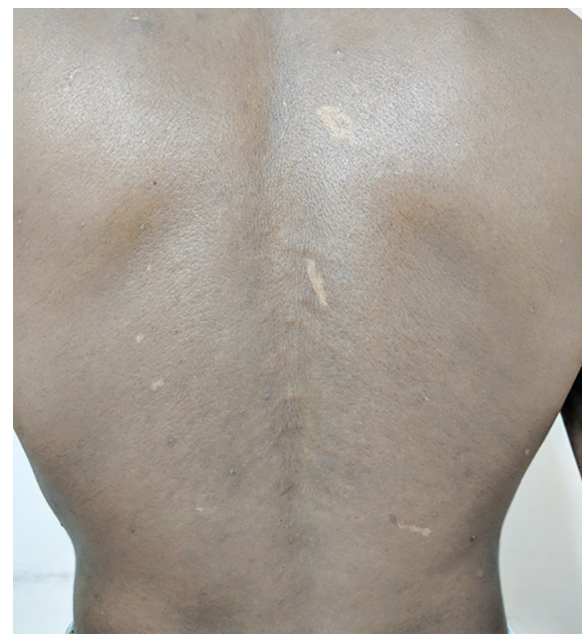

Fig. 1: Multiple well-defined hypopigmented macules and patches distributed over the back 


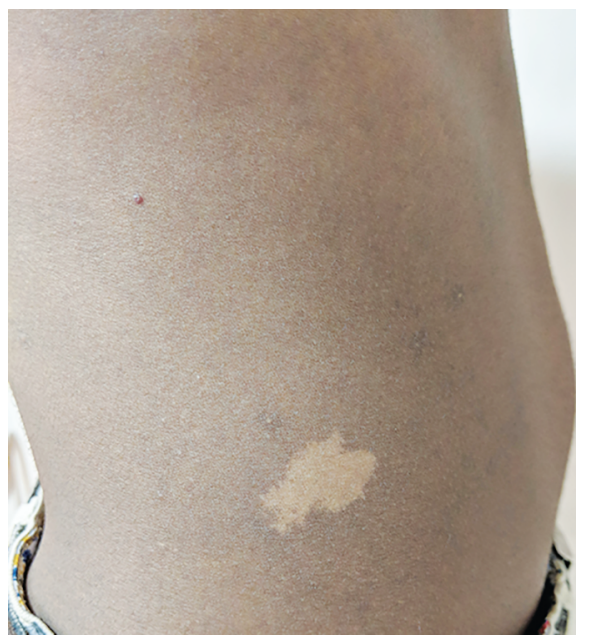

Fig. 2: Well-defined hypopigmented macule on the abdomen

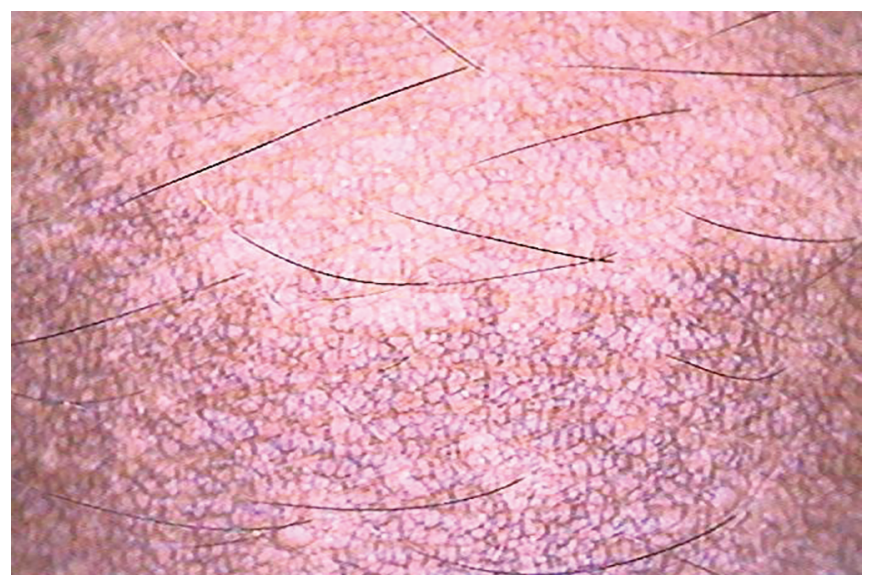

Fig. 4: Dermoscopic image of the macule, differentiating it from the adjacent normal skin showing normal skin markings, presence of welldefined margins, normal-looking hair, and yellow and white dots in polarized light. Loss of pigment network is evident

or a child develops a single large irregular area of hypo- or depigmentation. ${ }^{1}$ Nevus depigmentosus (ND) has serrated borders and is nonprogressive. ${ }^{4}$

It needs to be differentiated from other similar-looking hypopigmentary skin conditions like vitiligo, nevus anemicus, hypomelanosis of Ito, ash leaf macules of tuberous sclerosis, and indeterminate leprosy. ${ }^{4}$ It requires no treatment except when patient asks for it, for a better esthetic appearance. ${ }^{4}$

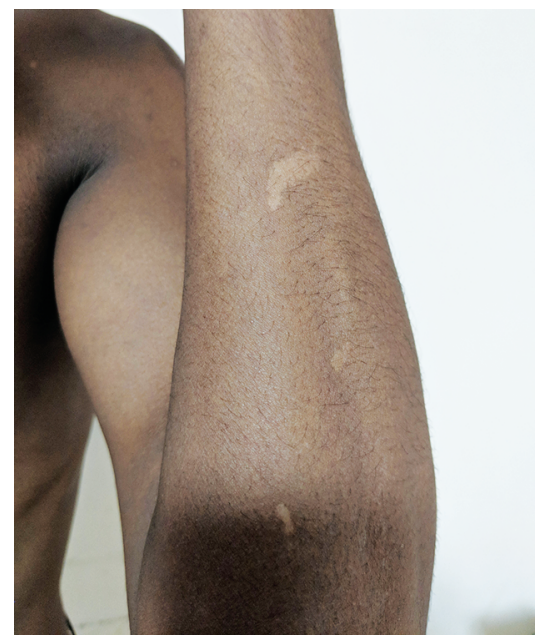

Fig. 3: Multiple hypopigmented macules over the forearm

There are three clinical variants: ${ }^{1,5}$

- Single well-defined lesion - the most common form ${ }^{1,5}$

- Segmental (dermatomal) nevus achromicus ${ }^{1,5}$

- Systematized form with whorls or streaks that are predominantly unilateral resembling hypomelanosis of Ito $^{1}$

Based on the size, the following classification can be made:

- Type I-size less than $10 \mathrm{~cm}^{2}$.

- Type Il-simplex form-size more than $10 \mathrm{~cm}^{2}$.

Our patient did not fit into any of the abovementioned three clinical types. He had multiple lesions that were generalized and asymmetrical. Considering the rarity of this kind of nevus achromicus, it was thought to be worthy of reporting.

\section{References}

1. Deb S, Sarkar R, Samanta AB. A brief review of nevus depigmentosus. Pigment Int 2014;1(2):56-58. DOI: 10.4103/2349-5847.147041.

2. Jindal R, Jain A, Gupta A, Shirazi N. Ash-leaf spots or naevus depigmentosus: a diagnostic challenge. 2013;2013:bcr2012007008. DOI: 10.1136/bcr-2012-007008.

3. Ankad BS, Shah S. Dermoscopy of nevus depigmentosus. Pigment Int 2017;4(2):121-123. DOI: 10.4103/2349-5847.219677.

4. Ullah F, Schwartz RA. Nevus depigmentosus: review of a mark of distinction. Int J Dermatol 2019;58(12):1366-1370.

5. Achromic naevus|DermNet NZ [Internet]. [cited 2020 May 13]. Available from: https://dermnetnz.org/topics/achromic-naevus/. 